\title{
MICRODOSING PSYCHEDELICS - LSD, WHERE COULD IT GO?
}

\section{Sara Pratas Penedos ${ }^{1,2}$; Inês Figueiredo 1,3 ; Pedro Azevedo²; Margarida Magalhães²; Liliana Moreno²; Ana Margarida Franco²; Inês Fonseca²; Nuno Ribeiro²; Maria João}

Freire'; João Nogueira $^{2}$; Joana Vieira²; Luís Madruga2; António Gamito ${ }^{2}$

${ }^{1}$ The authors contributed equally to this publication; ${ }^{2}$ Centro Hospitalar de Setúbal ${ }^{3}$;Hospital Prof. Doutor Fernando Fonseca, EPE \section{PE}

Fig. 1 - The LSD timeline

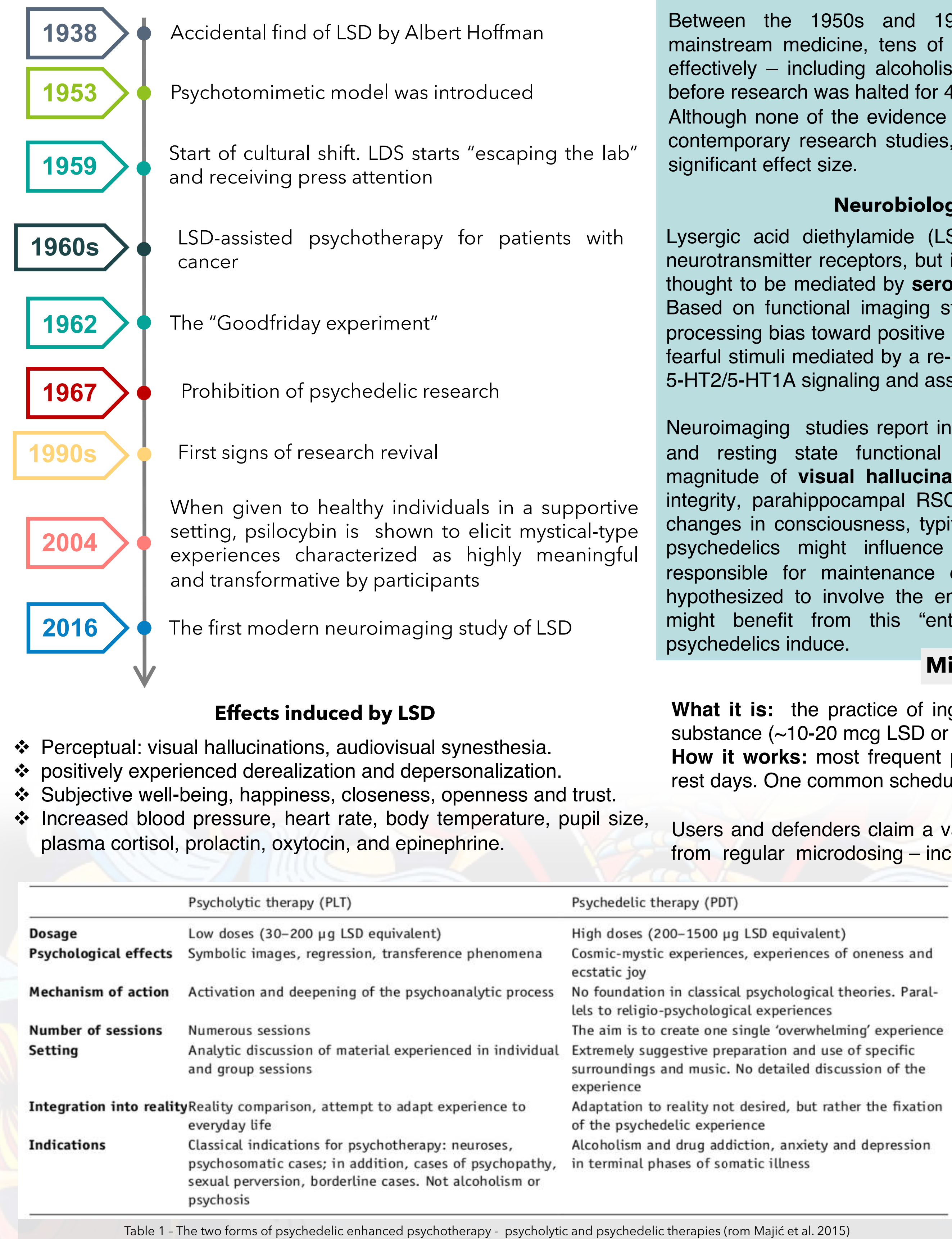

\section{WHAT WE KNOW}

60 s, psychedelic drugs had become patients had been treated , mood disorders, end of life anxiety Although none of the evidence was never as methodologically robust as contemporary research studies, when analyzed together they showed a

\section{Neurobiology and Pharmacology}

amide (LSD) has a high affinity for a range of tors, but its characteristic psychological effects are attenuate responses to re-balance of hippocampal/parahippocampal Neuroimaging studies report increased visual cortex cerebral blood flow connectivity (RSFC) - predicting the cono-dissolution, suggesting that responsible for maintenance of sense of "self". Disorders that are hypothesized to involve the emergence of "rigid" maladaptive circuitry might benefit from this "entropic" effect on cortical activity that

\section{Microdosing}

ingesting a very low dose of a psychedelic How it works: most frequent practice is interspersing dosing days with

Users and defenders claim a variety of psychological and social benefits ases in vitality, creativity, productivity,

social ability, focus, analytic thinking, positive mood, memory, mind- fulness and general wellbeing - while denying experiencing the alterations in consciousness and perception of typical doses.

There has been no specific research into the safety of microdosing, however research with higher doses of psychedelics suggests that these substances are relatively safe. In 2018 , a rise in subscribers to an online forum, reddit.com/microdosing exceeded 40,000 , doubling in less than 1 year

\section{WHAT WE NEED TO KNOW AND WHY}

There is today considerable popular interest in the practice of microdosing with indication of considerable levels of experimentation with psychedelics in the population ( 6-8\%). Past associations with uncontrolled recreational misuse and hedonistic approaches have negatively biased general opinion about psychedelic substances, preventing many clinicians from getting involved in research. Current findings suggest that popular accounts of the effects of microdosing may not match the experience of long term microdosers. This practice could offer benefits without the perceptual distortions and reduced need for expensive clinical oversight typical of full-dose psychedelic therapy Such a possibility calls for future investigation on the impact of microdosing for improved mental health, challenging popular opinion through contemporary, sober, and evidence-based research. An considerable obstacle may be funding - for now there is little support from the pharmaceutical industry since the drugs themselves are all off patent, the recommended doses are low and infrequent, and they do not require repeated long-term use. Most funding depends on private and charitable donations, which is slow and laborious.

\section{REFERENCES}

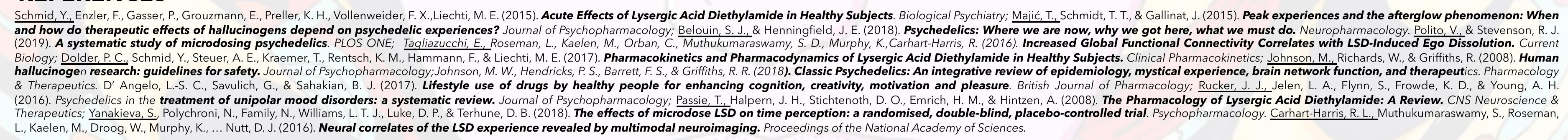

